\title{
Divided attention and prerecognition processing of spoken words and nonwords
}

\author{
WILLIAM P. WALLACE, THOMAS R. SHAFFER, MARTHA D. AMBERG, and VICKI L. SILVERS \\ University of Nevada, Reno, Nevada
}

\begin{abstract}
Three recognition memory experiments examined phonemic similarity and false recognition under conditions of divided attention. The manipulation was presumed to have little effect on automatic, perceptual influences of memory. Prior research demonstrated that false recognition of a test word (e.g., discrepancy) was higher if the study list included a nonword derived from the future test word by changing a phoneme near the end of the item (e.g., discrepan/l/y) relative to an early phoneme change (e.g., /l/iscrepancy). The difference has been attributed to automatic, implicit activation of test words during prerecognition processing of related nonwords. Three experiments demonstrated that the latechange condition also contributed to higher false recognition rates with divided attention at encoding. Dividing attention disrupted recognition memory of studied words in Experiments 1 and 3. Results are discussed in terms of their relevance for an interpretation emphasizing the automatic, implicit activation of candidate words that occurs in the course of identifying spoken words and nonwords.
\end{abstract}

Scientific curiosity is stimulated by counterintuitive phenomena; however, it is also reassuring when data conform to general expectations. Research on divided attention and memory has simultaneously met both of these conditions. Dividing attention during encoding by requiring participants to perform a second task while memory materials are presented impairs recall and recognition (Baddeley, Lewis, Eldridge, \& Thomson, 1984; Craik, Govoni, Naveh-Benjamin, \& Anderson, 1996; Hicks \& Marsh, 2000). This result is not surprising, since most individuals would concede that performance on a memory test should suffer if participants are unable to devote full attention to learning the relevant material during study. For certain types of memory tests, however, dividing attention during encoding appears to produce little decrement in performance (Mulligan, 1997, 1998; Mulligan \& Hartman, 1996; Naveh-Benjamin, Craik, Guez, \& Dori, 1998; Parkin, Reid, \& Russo, 1990; Parkin \& Russo, 1990; Wolters \& Prinsen, 1997).

The absence of a divided-attentioneffect has been linked to the indirect (implicit) nature of these memory tests. Generally, implicit memory tests that do not have a strong conceptual component are not impaired by divided attention at encoding (e.g., Jacoby, 1998; Mulligan, 1997, 1998; Mulligan \& Hartman, 1996; Parkin et al., 1990; SchmitterEdgecombe, 1999), although Isingrini, Vazou, and Leroy (1995) also demonstrated that category exemplar genera-

The authors wish to acknowledge the assistance of William Alexander and Mihoko Motoyama in collecting and scoring data. Correspondence should be addressed to W. P. Wallace, Department of Psychology, University of Nevada, Reno, NV 89557 (e-mail: wallace@unr.edu). tion was unaffected by divided attention. The most widely accepted interpretation of the dissociation of dividedattention effects is that performance on implicit memory tests without a strong conceptual component reflects "automatic" processing and, as a result, is minimally disrupted by division of attention during study (e.g., Jacoby, 1998; Mulligan, 1998).

In simple memory paradigms, word lists typically are presented for study, followed by a direct (explicit) recall or recognition test. For recognition, both studied words and nonstudied lures are tested, with participants indicating whether each item had been on the study list. Underwood (1965) was among the first to report that false positives to lures (incorrect claims that a new word had been presented during study) were predictable based on semantic relations. For example, false positives to bird were twice as high if robin, canary, blue jay, and sparrow appeared during study. He assumed that study words served as effective cues for implicit activation of related words and that implicit activation contributed to a sense of familiarity for the specific lures in question. Thus, a critical lure that had been activated implicitly would seem familiar and would be confused with studied words at the time of the recognition test.

The false-recognition phenomenon has been frequently replicated and extended (e.g., Anisfeld \& Knapp, 1968; Roediger \& McDermott, 1995; Sommers \& Lewis, 1999; Underwood \& Zimmerman, 1973), including demonstrations with implicit memory tests (McDermott, 1997). McDermott (1997) used lists of converging word associates developed by Deese (1959) and popularized by Roediger and McDermott (1995). Sets of 12 words were the most frequent associations given to a specific target word (e.g., door, glass, pane, shade, etc., for window). The re- 
sults showed that associative activation of critical target words occurred with perceptual (stem- and fragmentcompletion) and conceptual (word-association) implicit memory tests.

One variation on the false-recognition phenomenon involves testing new lures that share phonemes with studied items. Lures with a changed phoneme late in the item (e.g., barricade with either barrica/n/e or barracuda presented during study) are falsely recognized more often than lures with a changed phoneme early in the item (e.g., domineer with either /k/omineer or pioneer presented during study) (Dewhurst \& Hitch, 1997; Wallace, Malone, \& Spoo, 2000; Wallace, Stewart, \& Malone, 1995; Wallace, Stewart, Shaffer, \& Wilson, 1998; Wallace, Stewart, Sherman, \& Mellor, 1995).

Identification of spoken words does not occur simultaneously with speech onset. A listener may need to hear the beginning few hundred milliseconds of a spoken word to identify it (see Marslen-Wilson, 1987). In the course of recognizing spoken words and nonwords as they occur during study, lexical candidates representing potential solutions are "automatically" activated (e.g., Marslen-Wilson, 1987; McClelland \& Elman, 1986; Norris, 1994). Specific words activated implicitly during prerecognition phases of item presentations may seem "familiar" on a later recognition test, leading to a high rate of false-recognition errors. For example, on the basis of perceptual information that is available as a spoken stimulus unfolds over time, barricade is likely to be activated as a candidate during prerecognition processing of related stimuli, such as barrica/n/e or barracuda. It is less likely to be a candidate during early stages of processing stimuli, however, when initial phonemes differ, such as /n/arricade or decade. A word with ending phonemes in common with a target word (i.e., earlychange words, such as sand or send for hand) is also an effective prime (Slowiaczek, Nusbaum, \& Pisoni, 1987); however, the mechanism for this priming effect may not be triggered until postrecognition processing of the prime, or relatively late in the prerecognition processing stage, relative to processing a prime with initial phonemes in common with the target word (i.e., late-change words, such as dress or drill for dread).

The theoretical focus of the present research developed from the analysis of divided-attentioneffects on direct and indirect tests of memory, in combination with the prerecognition processing analysis of the differences in false recognition produced by late-change versus early-change "priming" stimuli. The contrast in false-recognition effects between early-change and late-change conditions is interpreted as resulting from data-driven perceptual processes. Therefore, this contrast in false-recognition effects should be relatively unaffected by division of attention during encoding. Although recognition of studied words should be impaired by divided attention, regardless of the effects that divided attention has on overall false recognition, it should not disrupt the automatic, prerecognition processing that is responsible for the false-recognition differences between early-change and late-change conditions.

\section{EXPERIMENT 1}

Experiment 1 was designed to evaluate the prediction based on the implication of automatic perceptual processes in theoretical interpretations of divided-attention and phonemic-similarity effects in false recognition. Although divided attention during encoding should disrupt some aspects of recognition performance, it should have little impact on performance driven by automatic processing. The predictions tested were (1) that there would be a greater increase in false recognition of critical lures following study of late-change nonwords relative to early-change nonwords and (2) that this relation would be present under both full- and divided-attention study procedures.

\section{Method}

Participants. A total of 64 introductory psychology students participated in this experiment. Thirty-two students were randomly assigned to each of the two attention groups. The participants were asked to volunteer for this experiment only if they were fluent in English and did not suffer from any known hearing loss.

Design. The experiment consisted of a single study trial of 108 successive items followed by a 50 -word recognition test. The study list included 20 nonwords presented three times each on the study list. Repetition frequency afforded multiple opportunities for prerecognition activation of the critical test words. Underwood's (1965) initial false-recognition experiment produced a false-recognition effect with antonyms when the critical eliciting stimuli were presented three times each during study, but not when they were presented only a single time.

There were 28 words on the study list: 8 serial position buffers presented in the first four and final four list positions, 10 test words that were presented three times each, and 10 test words that were presented a single time. Repetition of studied words was manipulated, although we were not interested in this variable per se. We know that three study-trial presentations produce higher recognition scores than one presentation (e.g., Wallace et al., 2000; Wallace, Stewart, \& Malone, 1995; Wallace, Stewart, Sherman, \& Mellor, 1995). Study-trial repetition was varied simply to create differences in degree of familiarity or "strength" among the class of old test words. This may not have been necessary - it was simply done to avoid a situation for which the only studied words tested were relatively uniform in strength.

The recognition test list consisted of 20 studied words (10 presented three times and 10 presented a single time during study) and 30 new words. There were 20 new test words related to nonwords that appeared on the study list and 10 new test words unrelated to studied nonwords. The basis of the relation between respective test words and studied nonwords was phonemic: Each nonword was derived from a test word by replacing one phoneme. For 10 of the test words and their respective derived nonwords, the phoneme substitution occurred early in the item (e.g., / k/rosperity for prosperity); for 10 exemplars, it occurred late (e.g., vitali/r/y for vitality).

Four versions of study lists were created with specific test words represented equally often as (1) old words presented three times during study, (2) new control words unrelated to studied nonwords, (3) new experimental words related to studied nonwords based on late-phoneme substitutions, and (4) new experimental words related to studied nonwords based on early-phoneme substitutions. Old words presented a single time during study were not included in this rotation because it is well established that three presentations of words on a study list result in a higher correct recognition rate relative to a single presentation (e.g., Wallace et al., 2000, reported hit rates of $68 \%$ and $90 \%$ for words presented one time and three times, respectively). 
Two different groups of students participated in the experiment. The defining difference in their treatment occurred during spoken presentation of each study item. During study, a divided-attentio n group had to categorize sets of three numbers that appeared simultaneously with onset of each spoken item. The number-categorization task was similar to digit-monitoring tasks used by others (e.g., Mulligan, 1998) in which participants had to tap a pen on the desk when they heard three successive odd numbers. Because the critical words and nonwords studied in the present experiment were spoken, digit monitoring was modified for visual presentation and to avoid distracting sounds (tapping of a pen, verbal feedback from the experimenter). The primary objective of this task was to create a diversion concurrent with the first few hundred milliseconds of prerecognition processing. The participants heard a series of words and nonwords during study, and a different three-digit number was presented concurrently with each study item. A full-attention group was unencumbered by the number-categorization task during study. Attention was varied between groups so that the participant would not be able to devote part of an interitem interval for a full-attention item to rehearse a previously presented divided-attention item.

Materials. Four categories of test words were equally represented in each of the major within-list conditions. The majority of the words were taken from previous experiments (Wallace, Stewart, Sherman, \& Mellor, 1995), with additional words (about 25\%) selected from word-association norms (Postman \& Keppel, 1970). Test words ranged in length from 2 to 4 syllables, 5 to 14 letters, and 5 to 12 phonemes. Early-change and late-change derived nonwords were created for each of the 40 critical test words simply by making a legal phoneme substitution (new adjacent phonemes appear in real English words) at or near the beginning or ending of the word (e.g., /b/elegram, a/l/enue, /k/rosperity, telegra/b/, ave/l/ue, prosperi/k/y; see the Appendix). The remaining 18 words (8 nontested serial position buffers and 10 test words that were presented a single time during study) were also 2- to 4-syllable words.

Presentation order of items on study and test trials was random, with the restriction that repetitions of items during study were separated by a minimum of five other items. Spoken items were created using a sound-editing package (SoundEdit 16, version 2) and a Power Macintosh 6400/200 computer. A male speaker recorded each item separately using a high-quality microphone (Audio Technica Model AT802). The resulting audio file was then low-pass filtered, amplified, and digitized at $44 \mathrm{kHz}$ (16 bits) and stored on the hard drive of a Star Max 3000/180 microcomputer. Lists were constructed using the PsyScope research package (Cohen, MacWhinney, Flatt, \& Provost, 1993). Stimuli were presented over highquality headphones (Optimus Pro-50MX).

Procedure. The experiment involved five steps: (1) The participants were given specific instructions appropriate for the fullattention or divided-attention conditions. They were informed that there would be a subsequent memory test, and that details for the test procedure would be explained later. (2) Instructions were followed by a 5-word practice list to illustrate procedures and to allow the participants to adjust the recording volume to a comfortable level. (3) The experiment began after the practice list. Words and nonwords on the study list were presented at the rate of 1 item every $3 \mathrm{sec}$. (4) At the conclusion of the 108-item study list, the experimenter explained procedures for the recognition test, informing the participants to say "old" or "new" in response to each spoken test word ("old" meant it had been presented during study, and "new" meant it had not been presented before). (5) The 50-word test list was then presented at the rate of 1 word every $3 \mathrm{sec}$.

For the participants in the divided-atten tion group, three single-digit numbers were presented on the computer screen, with the duration for each yoked to the corresponding spoken-item duration (most were in the range of 600-900 msec). The number display coincided with onset of each spoken study item. The participants were instructed to respond as quickly and accurately as possible by pressing one of two buttons: the button marked odd if the majority of digits were odd numbers (e.g., "9 63 ") or the button marked even if the majority of digits were even numbers (e.g., "7 4 2").

\section{Results}

Correct recognition of studied words. Twenty test words were "old" words that appeared either one or three times on the study list. Contrasts between full- and divided-attention groups in correct recognition involved identical test words; however, the comparison between words presented one or three times during study involved different words. The proportions of correct "old" responses with full attention were .59 for studied words presented once and .87 for studied words presented three times. With divided attention, the proportions of "old" responses were .48 and .76 following one and three study presentations, respectively. A mixed two-factor analysis of variance (ANOVA) with participants as a random factor $\left(F_{1}\right)$, indicated that both main effects were significant. The proportion correct was higher following three study trial repetitions $\left[F_{1}(1,62)=132.28, M S_{\mathrm{e}}=0.02\right.$, $p<.05]$ and with full attention $\left[F_{1}(1,62)=9.83, M S_{\mathrm{e}}=\right.$ $0.04, p<.05]$. The interaction was not significant $\left(F_{1}<\right.$ 1.0). Statistical analyses were also done with items as a random factor $\left(F_{2}\right)$. The results were similar to the analysis with participants as a random factor $\left[F_{2}(1,48)=33.21\right.$, $M S_{\mathrm{e}}=0.04, p<.05$, for the study trial repetition contrast; $F_{2}(1,48)=11.36, M S_{\mathrm{e}}=0.03, p<.05$, for the full- vs. divided-attentioncontrast]. The interaction was not significant $\left(F_{2}<1.0\right)$. The divided-attention procedure used in this experiment clearly lowered the success rate in recognizing words from the study list.

The divided-attention task proved to be relatively easy, given that the proportion of incorrect "odd/even" classifications for the 108 judgments was .04. Performance on the digitclassification task was not correlated with recognition test performance ( $r=-.05$, between correct "old" recognition and classification errors). Similarly, the overall number of false recognitions (summarized in the next section) was not correlated with classification errors $(r=+.03)$.

False recognition of lures. The means and standard errors for proportions of "old" responses are summarized in the top two rows of Table 1 . The data of primary interest are the incorrect "old" responses given to lures (control, late-change, and early-change lures). It is apparent from Table 1 that three study presentations of a phonemically related nonword substantially increased the proportion of false positives relative to the controls. Of particular interest is the fact that the late-change phonemic relation contributed to a higher false-recognition rate than did the early-change condition for both full-attention and dividedattention groups.

The statistical analysis focused on the experimental conditions contrasting late with early phoneme changes in derived nonwords. Analyses were done using both participants $\left(F_{1}\right)$ and items $\left(F_{2}\right)$ as random factors. It should be noted that attention was a between-participant and a within-item variable; thus, the statistical design treating 
Table 1

Proportion of "Old" Responses and Standard Errors Under Conditions of Full Attention and Divided Attention to Studied Words and to Late-Change, Early-Change, and Control Lures

\begin{tabular}{|c|c|c|c|c|c|c|c|c|}
\hline & \multicolumn{8}{|c|}{ Type of Test Word } \\
\hline & \multicolumn{2}{|c|}{ Studied } & \multicolumn{2}{|c|}{ Late Change } & \multicolumn{2}{|c|}{ Early Change } & \multicolumn{2}{|c|}{ Control } \\
\hline & $p($ old $)$ & $S E$ & $p($ old $)$ & $S E$ & $p($ old $)$ & $S E$ & $p($ old $)$ & $S E$ \\
\hline \multicolumn{9}{|c|}{ Experiment 1} \\
\hline Full attention & .869 & .022 & .472 & .038 & .369 & .043 & .106 & .021 \\
\hline Divided attention & .762 & .031 & .497 & .030 & .397 & .027 & .125 & .022 \\
\hline \multicolumn{9}{|c|}{ Experiment 2} \\
\hline Full attention & .816 & .030 & .345 & .031 & .250 & .032 & .062 & .014 \\
\hline Divided attention & .819 & .026 & .368 & .028 & .317 & .033 & .084 & .018 \\
\hline \multicolumn{9}{|c|}{ Experiment 3} \\
\hline \multicolumn{9}{|l|}{ Silent Study } \\
\hline Full attention & .856 & .031 & .438 & .050 & .338 & .040 & .122 & .028 \\
\hline Divided attention & .731 & .038 & .412 & .040 & .350 & .048 & & \\
\hline \multicolumn{9}{|l|}{ Vocal Study } \\
\hline Full attention & .912 & .024 & .519 & .041 & .350 & .046 & .059 & .015 \\
\hline Divided attention & .688 & .037 & .394 & .052 & .294 & .037 & & \\
\hline
\end{tabular}

Note-By definition, control test words in Experiment 3 did not correspond to specific items on the study list; hence, they could not be related to full attention or divided attention study conditions.

items as a random factor should be the more sensitive of the two. In most cases, the analyses produced identical statistical conclusions. The $p \leq .05$ decision rule was used for all statistical evaluations.

There were two results from the statistical analyses that warrant emphasis. First, there was a significantly higher proportion of false-recognition errors for the late-change condition than for the early-change condition $\left[F_{1}(1,62)=\right.$ $\left.14.88, M S_{\mathrm{e}}=0.02 ; F_{2}(1,39)=5.94, M S_{\mathrm{e}}=0.07\right]$. Second, the interaction was not significant (both $F_{1}$ and $F_{2}<$ 1.0). An implication of the nonsignificant interaction is that false-recognition errors to experimental lures were similar with both full- and divided-attention study procedures. The difference in false-recognition errors between full- and divided-attention groups was not significant $\left(F_{1}<1.0\right.$, and $\left.F_{2}=1.12\right)$. For all comparisons with control lures, false-recognition rates were higher for early- and late-change conditions, with all contrasts significant at $p<$ .05 (analyses across both participants and items).

\section{Discussion}

The purpose of this experiment was to examine locus of phonemic similarity effects in false recognition when attention was divided between two tasks during original encoding. Prior research demonstrated that, under fullattention conditions, late-change test sets (e.g., patriotic and patriotilf/) had a higher false-recognition rate than did early-change test sets (e.g., patriotic and /f/atriotic; see Wallace et al., 2000; Wallace, Stewart, Shaffer, \& Wilson, 1998; Wallace, Stewart, Sherman, \& Mellor, 1995). The effect was replicated in the present experiment and extended to study conditions that required dividing attention at the onset of the spoken study items. This extension is theoretically important because of its relevance for a prere- cognition processing analysis. The interpretation of the false-recognition data under conditions of divided attention is that potential solution words, likely including the critical test lures in the late-change condition when identical beginning phonemes are involved, are automatically activated in the course of perceptual recognition of the spoken study items.

It is common to interpret responses of "old" to lures as false-positive errors. However, for experiments examining phonemic relations, the critical lures are nearly identical to nonword study items. If a participant misperceived a nonword on the study list (e.g., /l/iscrepancy) as a future test lure (e.g., discrepancy), then, for that participant, discrepancy is effectively an "old" study word. We have assumed that participants perceive the nonwords as intended. In Experiment 2, one procedural variation was introduced in a replication of Experiment 1 (viz., the participants had to repeat aloud each word and nonword on the study list immediately after it was spoken). Wallace and Collins (1991) reported that fewer than $2 \%$ of words spoken at a normal rate were misperceived; however, they did not include nonwords in their experiment. In the present experiment, the participants' naming responses were recorded, and any test word that was emitted as a misperceived study item was excluded from the subsequent data analyses.

\section{EXPERIMENT 2}

The purpose of Experiment 2 was to provide a replication of Experiment 1, removing from consideration test words that were given as misperceived identifications to spoken items during study. It is important that "recognition" of a new test lure actually represents a false recognition. In Experiment 1, dividing attention during encod- 
ing did not alter the pattern of false-recognition errors as a function of locus of a phoneme substitution between studied nonwords and corresponding test words. Given the theoretical significance attached to this result, it seemed prudent to confirm its reliability through replication.

\section{Method}

The design, materials, and procedures for Experiment 2 followed those described for Experiment 1 in all respects except one. During the study trial in this experiment, each participant was asked to repeat aloud each word or nonword immediately after it was spoken. Thirty-two introductory psychology students, who met the same language and hearing criteria as in Experiment 1, were randomly assigned to each group.

\section{Results}

Correct recognition of studied words. Three repetitions of studied words produced significantly higher rates of correct recognition relative to one study-trial presentation $\left[F_{1}(1,62)=67.00, M S_{\mathrm{e}}=0.02 ; F_{2}(1,48)=13.95\right.$, $\left.M S_{\mathrm{e}}=0.05\right]$. The proportions correct with full attention were .64 for studied words presented once and .82 for studied words presented three times. In the divided-attention group, the respective proportions were .58 and .82 . Unlike in Experiment 1, however, divided attention did not result in a significantly lower correct recognition rate for studied words: $F_{1}$ and $F_{2}$ for the main effect of attention and the interaction were less than 1.0. The participants made few errors in performance on the odd-even digit-classification task (a mean error rate of .06). Correlations between the two tasks could not be computed for this experiment due to an error in timing: Participant identification codes were destroyed before hard copies of the digit-classification task were created and attached to the respective recognition performance protocols.

False recognition of lures. The procedural variation introduced in this experiment required the participants to repeat aloud each study item. If a participant said the actual test word to any one of the three study-list presentations of its derived nonword, that item was excluded from the analysis. This type of misperception occurred for 11 nonwords during study (less than 1\% of the 1,280 opportunities, on the basis of 64 participants and 20 derived nonwords on the study list).

The proportions of false recognition errors to control lures and to experimental lures related to studied nonwords are presented in the middle two rows of Table 1. Although the overall error rates were lower than in Experiment 1, the two experiments were consistent in the most important respect. Study presentations of phonemically related nonwords increased false-recognition rates to lures substantially above the control rate, and late-change derived nonwords contributed to a higher false recognition rate than did early-change derived nonwords.

The results of the statistical analyses were consistent with the main results reported in Experiment 1. There was a higher proportion of false recognition errors in the latechange condition than in the early-change condition $\left[F_{1}(1,62)=10.33, M S_{\mathrm{e}}=0.02 ; F_{2}(1,39)=5.25, M S_{\mathrm{e}}=\right.$
0.04]. The effect was consistent with both full and divided attention-that is, the interaction was not significant $\left(F_{1}<1.0\right.$, and $\left.F_{2}=1.03\right)$. The proportion of false recognition errors was higher under divided attention than under full attention. The attention effect was not significant in the analysis with participants as a random variable (a between-participant variable) $\left[F_{1}(1,62)=1.44, M S_{\mathrm{e}}=\right.$ $0.05]$; however, it was significant in the analysis across items (a within-item variable) $\left[F_{2}(1,39)=4.46, M S_{\mathrm{e}}=\right.$ $0.02]$. For all comparisons with the control condition, falserecognition rates were higher for experimental lures, with all contrasts significant at $p<.05$ in analyses across both participants and items.

\section{Discussion}

The results of Experiment 2 replicated the most important results of Experiment 1. False recognition of new test words was highest for lures that were related to nonword study items by virtue of having the same beginning phonemes (late change), and dividing attention during encoding did not eliminate this effect. However, the general effects of dividing attention during study on later recognition performance were not clear. Correct recognition of studied words in Experiment 1 was significantly lower for the divided-attention group, than for the full-attention group. In Experiment 2, the two attention groups were equivalent. False recognition of lures was consistently higher with divided attention, but the difference was statistically significant only for the analysis across experimental lures in Experiment 2 with items as a random factor. The reasons for the different results across experiments regarding the effects of this divided-attentiontask on correct recognition of studied words (and, possibly, overall false-recognition effects) are not clearly understood at this time. Given that Experiment 1 used a silent study procedure and that Experiment 2 required that the participants say items aloud during study, a third experiment was done that included both silent and vocal study conditions.

\section{EXPERIMENT 3}

The purpose of Experiment 3 was to compare, in a single experiment, the divided- and full-attention conditions with silent study (Experiment 1) and when participants are required to repeat items aloud as they hear them (Experiment 2). This replication was motivated by three primary concerns. First, the special interest in the false-recognition effect based on the locus of phonemic substitutions in derived nonwords and the persistence of this effect with divided attention during study provided the rationale for conducting a replication. Second, the discrepancies between the first two experiments concerning the disruptive effects of divided attention on recognition of studied words provided motivation to repeat the essential features of Experiments 1 and 2 in a single experiment. Third, division of attention is frequently manipulated as a within-participant variable, rather than the between-participant manipulation used in the first two experiments. Thus, the third experi- 
ment involved a silent study group and a vocal naming group exposed to a long study list of words and nonwords. Half of the items on each study list were accompanied by a visual display of three digits for the odd-even classification task (divided-attention items), and half were accompanied by a visual display of three asterisks, signaling that there were no additional task demands (full-attention items).

\section{Method}

Experiment 3 may be thought of procedurally as a combination of Experiments 1 and 2. The study and test lists were identical to the first two experiments, as was the divided-attention task. Sixty-four introductory psychology students were randomly assigned to either a silent study group or a vocal study group, with 32 participants in each group. The major procedural departure from Experiments 1 and 2 involved the digit-classification task that defined divided attention. For both the silent study group and the vocal study group, a random half of the study-list items were accompanied by a simultaneous visual display of three digits, and half were accompanied by a simultaneous visual display of three asterisks (there were two versions of the list so that specific items appeared equally often in each attention condition). The duration of respective displays was yoked to spoken-item durations, with most exposures in the range of 600-900 msec. When numbers appeared, the participants were required to classify digits as "odd" or "even" as rapidly and accurately as they could by pressing the corresponding buttons, as in Experiments 1 and 2.

As in Experiments 1 and 2, the main experimental conditions involved recognition test words that had appeared either one or three times during study and three types of new test words (the corresponding late-change derived nonwords, early-change derived nonwords, or neither were presented on the study list). There were eight versions of study lists so that each test word was represented equally often as full- and divided-attention items for four item conditions (studied words presented three times and the three types of new test words). There were also 10 test words presented a single time during study, balanced across full-attention and divided-attention conditions. There were 40 critical test word exemplars rotated through the eight conditions, with five exemplars in each set (effectively 10 control exemplars given that attention at study was not defined for control lures). In all other regards, procedures during study and test trials followed those used in Experiments 1 and 2.

\section{Results}

Correct recognition of studied words. With silent study and full attention, the proportions of correct "old" responses were .53 to test words presented a single time on the study list and .86 to test words presented three times during study. For divided attention, the proportions of correct "old" responses were .51 and .73 following one and three study-trial repetitions, respectively. The corresponding proportions with full attention and vocal study were .58 and .91 . For divided attention, the proportions of correct "old" responses were .49 and .69 , respectively. An ANOVA on proportions of correct "old" responses revealed that the difference between one and three study-trial repetitions was significant $\left[F_{1}(1,62)=\right.$ $\left.175.09, M S_{\mathrm{e}}=0.03 ; F_{2}(1,48)=26.29, M S_{\mathrm{e}}=0.09\right]$. Correct recognition was also significantly higher for full attention than for divided attention $\left[F_{1}(1,62)=22.46\right.$, $\left.M S_{\mathrm{e}}=0.04 ; F_{2}(1,48)=37.19, M S_{\mathrm{e}}=0.03\right]$, and the attention effect was more pronounced with three repetitions during study. The interaction between attention condition and study repetitions was significant across participants $\left[F_{1}(1,62)=5.32, M S_{\mathrm{e}}=0.04\right]$, but fell short of acceptable levels of statistical significance in the analysis across items $\left[F_{2}(1,48)=3.72, M S_{\mathrm{e}}=0.03\right]$. The difference between silent study and vocal study groups was not significant (both $F_{1}$ and $F_{2}<1.0$ ).

The only other contrast that produced an $F$ ratio greater than 1.0 involved the nonsignificant interaction between attention and silent versus vocal study $\left[F_{1}(1,62)=3.22\right.$, $\left.M S_{\mathrm{e}}=0.04 ; F_{2}(1,48)=3.70, M S_{\mathrm{e}}=0.03\right]$. In this experiment, the disruption in correct recognition of studied words resulting from divided attention was numerically larger in the vocal study group (.74 vs. .59) than in the silent study group (.70 vs. .62). The average error rates on the digitclassification task were .09 for the silent study group and .06 for the vocal study group. Performance on the digitclassification task was not correlated with recognition test performance $(r=-.10$, between correct old recognition and classification errors). Similarly, the overall number of false recognitions (summarized in the next section) was not correlated with classification errors $(r=+.09)$.

False recognition of lures. Each of 32 participants in the vocal study group gave an overt naming response to 20 derived nonwords (a total of 640 responses). Only 3 nonwords were misperceived as their base words (less than $1 \%$ ). False-recognition rates to lures (excluding the 3 misperceived derived nonword sets) as a function of naming requirements during study, phonemic relations between study and test items, and attention conditions are summarized in the lower half of Table 1 . These data show that the late-change condition produced more false recognitions than did the early-change condition.

The results of an ANOVA on proportion of "old" responses to experimental lures were consistent with those of Experiments 1 and 2. There was a higher proportion of false recognitions to lures in the late-change condition than in the early-change condition $\left[F_{1}(1,62)=16.95, M S_{\mathrm{e}}=\right.$ $\left.0.04 ; F_{2}(1,39)=5.60, M S_{\mathrm{e}}=0.19\right]$. A surprising result was that overall false-recognition rates were numerically higher with full attention than with divided attention. The difference was not significant in the analysis with participants as a random variable $\left[F_{1}(1,62)=3.06, M S_{\mathrm{e}}=\right.$ $0.05]$; however, it was significant across items $\left[F_{2}(1,39)=\right.$ $\left.5.18, M S_{\mathrm{e}}=0.05\right]$. The difference between full and divided attention appeared more pronounced when the participants repeated the words and nonwords during study; however, the interaction was not significant in the analysis across participants, and it fell just short of significance in the analysis across items $\left[F_{1}(1,62)=2.32, M S_{\mathrm{e}}=0.05\right.$; $\left.F_{2}(1,39)=4.07, M S_{\mathrm{e}}=0.04\right]$. For both analyses, the $F$ ratios for all remaining effects were less than 1.0. Important among the nonsignificant interactions was the one involving attention and locus of phonemic change for experimental lures: Late-change differences between studied nonwords and their corresponding test words resulted in more false recognitions than did early-change differences, and this was true for both full- and divided-attention conditions. 


\section{Discussion}

Phonemic overlap between studied nonwords and new words on a recognition test produced a high rate of falserecognition errors. The error rate was consistently higher for studied nonwords derived from their tested base words by having a phoneme substitution near the end of the item, relative to a phoneme substitution near the beginning. Experiment 3 confirmed that this phenomenon was present with divided attention at encoding manipulated as a within-participant variable. With regard to correct recognition of studied words, the results of Experiment 3 replicated those of Experiment 1. A concurrent digitclassification task during encoding resulted in a lower hit rate to studied words on a recognition test, relative to the hit rate for studied words that were presented without requirements for digit classifications. Because this effect was present for the group that had to repeat items aloud during study, the absence of an effect in Experiment 2 cannot be attributed to the naming requirements.

The overall effect of divided attention on false recognitions also varied across experiments. False-recognition rates were higher for divided attention than for full attention in Experiments 1 and 2, but there was only modest statistical support for reliability of the differences (Experiment 2 in the analysis with items as a random factor). In Experiment 3, however, the overall false-recognition rate was actually lower with divided attention, with the main effect for attention significant only in the analysis with items as a random factor. Although the present results are consistent with the results of other studies that indicate that recognition is not immune to disruption from a concurrent encoding task that divides attention, the general effects of divided attention at encoding may be more fragile in recognition than in recall (see Baddeley et al., 1984; Hicks \& Marsh, 2000; Naveh-Benjamin et al., 1998).

\section{GENERAL DISCUSSION}

Dividing attention at encoding has been a successful dissociation procedure for differentiating implicit and explicit memory. Divided attention impairs performance on tests of explicit memory; however, it has little effect on performance with perceptually driven tests of implicit memory (e.g., Mulligan, 1998; Schmitter-Edgecombe, 1999). A general interpretation of this dissociation is that attention is relevant for consciously controlled factors in memory but has little impact on factors relevant for memory that occur automatically (Jacoby, 1998). Items on a spoken study list that have identical beginning phonemes with new test words (the late-change manipulation in the present experiments) produce more false-recognition errors than do items that have identical ending phonemes (the early-change condition) (e.g., Wallace et al., 1998; Wallace, Stewart, Sherman, \& Mellor, 1995). This result has been attributed to automatic, implicit activation of a test word as a candidate during early stages of processing a spoken word.
Despite some variation across experiments in the disruptive influence that divided attention has on the ability of the participants to recognize previously studied words, one important result was apparent. The three experiments were consistent in demonstrating that false-recognition rates to test lures (e.g., prosperity) were higher when derived nonwords on the study list had late phoneme changes (e.g., prosperi/k/y) than when they had early phoneme changes (e.g., /k/rosperity). The differences between late- and earlychange conditions ranged from .051 to .169 , with an average of .098 (nearly one false recognition more to latechange items than to early-change items per individual). Dividing attention left this false-recognition phenomenon intact, presumably because it did not disrupt the implicit activation of lexical candidates that occurred during perceptual recognition of spoken words and nonwords.

Although dividing attention at encoding appeared to disrupt recognition memory for studied words, it did not produce consistent effects on overall false-recognition rates. The pattern of false-recognition errors as a function of phonemic similarity between pairs of new test words and study-list nonwords was the same with both full and divided attention during encoding. Overall, false-recognition rates for all lures were not affected by the divided-attention task in Experiment 1, they were slightly elevated in Experiment 2 (significantly higher with divided attention in the within-item ANOVA), and they were slightly depressed in Experiment 3 (significantly lower with divided attention in the within-item ANOVA). Within the context of a two-factor theory of recognition memory (Jacoby, 1983a, 1983b; Jacoby \& Dallas, 1981; Mandler, 1980), dividing attention appeared to disrupt "recollection" of studied words (see Joordens \& Hockley, 2000). The impact of divided attention on "familiarity" is less clear with regard to an influence on general false-recognition rates. Divided attention at encoding, however, did not appear to impact familiarity resulting from prerecognition activation of lexical candidates during spoken word recognition.

The divided-attention task in the present experiments was designed to compete with the initial encoding of spoken words and nonwords that begins with onset of each spoken stimulus. Although the digit-classification task made attention demands that carried into postrecognition processing, it was a manageable task, normally completed quite successfully within the 3 -sec interval that separated successive study items. Thus, contributions from postrecognition processing were not eliminated in the present experiments. The special status of initial phonemes for recognizing spoken words has been a topic of theoretical interest and debate (see Marslen-Wilson, 1990; Monsell \& Hirsh, 1998; Slowiaczek et al., 1987). The present data, however, are not informative about whether nonwords that share ending phonemes with a target word are activated as potential lexical candidates prior to identification. Because postrecognition word activation of the critical target words was not neutralized in these experiments, we cannot determine whether all of the differences in false 
recognition between control lures and the early-change experimental lures (e.g., ceremony following the appearance of /t/eremony during study) are due to prerecognition processing, postrecognition processing, or a combination of the two.

Divided attention at encoding may force learners to rely on a shallow, phonemic-based processing (Hicks \& Marsh, 2000; Naveh-Benjamin, Craik, Gavrilescu, \& Anderson, 2000). It is presumed that implicit activation of potential solution words during prerecognition processing of words and nonwords is phonemically driven and an automatic consequence of stimulus reception. The differences in false recognition among early- and late-change conditions were attributed to implicit activation processing and its resultant effects on "familiarity values" of new test words. From this perspective, dividing attention at encoding should not alter relative false-recognition rates among conditions. However, dividing attention at encoding should impact false-recognition rates that are driven by a deep level of semantic processing. In the present experiments, general effects of divided attention on false recognition were inconsistent. It should be noted that semantic relations among study items and test lures were deliberately minimized in list construction, thus "deep" levels of processing that occurred during study may not have been a major contributing factor for inducing false recognition of the specific test lures used in these experiments.

\section{REFERENCES}

ANISFELD, M., \& KNAPP, M. (1968). Association, synonymity, and directionality in false recognition. Journal of Experimental Psychology, 77, 171-179.

Baddeley, A., Lewis, V., Eldridge, M., \& Thomson, N. (1984). Attention and retrieval from long-term memory. Journal of Experimental Psychology: General, 113, 518-540.

Cohen, J., MacWhinney, B., Flatt, M., \& Provost, J. (1993). PsyScope: An interactive graphic system for designing and controlling experiments in the psychology laboratory using Macintosh computers. Behavior Research Methods, Instruments, \& Computers, 25, 257-271.

Craik, F. I. M., Govoni, R., Naveh-Benjamin, M., \& Anderson, N. D. (1996). The effects of divided attention on encoding and retrieval processes in human memory. Journal of Experimental Psychology: General, 125, 159-180.

DEESE, J. A. (1959). On the prediction of occurrence of particular verbal intrusions in immediate recall. Journal of Experimental Psychology, 58, $17-22$.

Dewhurst, S. A., \& Hitch, G. J. (1997). Illusions of familiarity caused by cohort activation. Psychonomic Bulletin \& Review, 4, 566-571.

Hicks, J. L., \& MARSH, R. L. (2000). Toward specifying the attentional demands of recognition memory. Journal of Experimental Psychology: Learning, Memory, \& Cognition, 26, 1483-1498.

Isingrini, M., Vazou, F., \& Leroy, P. (1995). Dissociation of implicit and explicit memory tests: Effect of age and divided attention on category exemplar generation and cued recall. Memory \& Cognition, 23, 462-467.

JACOBY, L. L. (1983a). Perceptual enhancement: Persistent effects of an experience. Journal of Experimental Psychology: Learning, Memory, \& Cognition, 9, 21-38.

JACOBY, L. L. (1983b). Remembering the data: Analyzing interactive processes in reading. Journal of Verbal Learning \& Verbal Behavior, 22, 485-508.

JACOBY, L. L. (1998). Invariance in automatic influences of memory: Toward a user's guide for the process-dissociation procedure. Jour- nal of Experimental Psychology: Learning, Memory, \& Cognition, 24, 3-26.

JACOBY, L. L., \& DALlas, M. (1981). On the relationship between autobiographical memory and perceptual learning. Journal of Experimental Psychology: General, 110, 306-340.

Joordens, S., \& HockLeY, W. E. (2000). Recollection and familiarity through the looking glass: When old does not mirror new. Journal of Experimental Psychology: Learning, Memory, \& Cognition, 26, $1534-1555$

Mandler, G. (1980). Recognizing: The judgment of previous occurrence. Psychological Review, 87, 252-271.

MARSLEN-WiLson, W. D. (1987). Functional parallelism in spoken word recognition. Cognition, 25, 71-102.

MARSLEN-Wilson, W. D. (1990). Activation, competition, and frequency in lexical access. In G. T. M. Altmann (Ed.), Cognitive models of speech processing: Psycholinguistic and computational perspectives (pp. 148-172). Cambridge, MA: Cambridge University Press.

McClelland, J. L., \& Elman, J. L. (1986). The TRACE model of speech perception. Psychological Review, 76, 165-178.

McDermott, K. B. (1997). Priming on perceptual implicit memory tests can be achieved through presentation of associates. Psychonomic Bulletin \& Review, 4, 582-586.

Monsell, S., \& HirSh, K. W. (1998). Competitor priming in spoken word recognition. Journal of Experimental Psychology: Learning, Memory, \& Cognition, 24, 1495-1520.

Mulligan, N. W. (1997). Attention and implicit memory tests: The effects of varying attentional load on conceptual priming. Memory \& Cognition, 25, 11-17.

Mulligan, N. W. (1998). The role of attention during encoding in implicit and explicit memory. Journal of Experimental Psychology: Learning, Memory, \& Cognition, 24, 27-47.

Mulligan, N. W., \& Hartman, M. (1996). Divided attention and indirect memory tests. Memory \& Cognition, 24, 453-465.

Naveh-Benjamin, M., Craik, F. I. M., Gavrilescu, D., \& Anderson, N. D. (2000). Asymmetry between encoding and retrieval processes: Evidence from divided attention and a calibration analysis. Memory \& Cognition, 28, 965-976.

Naveh-Benjamin, M., Craik, F. I. M., Guez, J., \& Dori, H. (1998). Effects of divided attention on encoding and retrieval processes in human memory: Further support for an asymmetry. Journal of Experimental Psychology: Learning, Memory, \& Cognition, 24, 1091-1104.

NorRIS, D. (1994). Shortlist: A connectionist model of continuous speech recognition. Cognition, 52, 189-234.

Parkin, A. J., ReID, T. K., \& Russo, R. (1990). On the differential nature of implicit and explicit memory. Memory \& Cognition, 18, 507-514.

PARKIN, A. J., \& Russo, R. (1990). Implicit and explicit memory and the automatic/effortful distinction. European Journal of Cognitive Psychology, 2, 71-80.

Postman, L., \& KePpel, G. (Ed.) (1970). Norms of word association. New York: Academic Press.

Roediger, H. L., III, \& McDermott, K. B. (1995). Creating false memories: Remembering words not presented in lists. Journal of Experimental Psychology: Learning, Memory, \& Cognition, 21, 803-814.

SchmitTER-EDGECOMbe, M. (1999). Effects of divided attention on perceptual and conceptual memory tests: An analysis using a processdissociation approach. Memory \& Cognition, 27, 512-525.

SlowiaczeK, L. M., Nusbaum, H. C., \& Pisoni, D. B. (1987). Phonological priming in auditory word recognition. Journal of Experimental Psychology: Learning, Memory, \& Cognition, 13, 64-75.

Sommers, M. S., \& LeWIS, B. P. (1999). Who really lives next door: Creating false memories with phonological neighbors. Journal of Memory \& Language, 40, 83-108.

UNDERWoOd, B. J. (1965). False recognition produced by implicit verbal responses. Journal of Experimental Psychology, 70, 122-129.

Underwood, B. J., \& Zimmerman, J. (1973). The syllable as a source of error in multisyllable word recognition. Journal of Verbal Learning \& Verbal Behavior, 12, 701-706.

Wallace, W. P., \& Collins, J. E. (1991). The influence on recognition of spoken words that are misperceived. Memory \& Cognition, 19, 498-506. 
Wallace, W. P., Malone, C. P., \& Spoo, A. D. (2000). Implicit word activation during prerecognition processing: False recognition and remember/know judgments. Psychonomic Bulletin \& Review, 7, 149-157.

Wallace, W. P., Stewart, M. T., \& Malone, C. P. (1995). Recognition memory errors produced by implicit activation of word candidates during the processing of spoken words. Journal of Memory \& Language, 34, 417-439.

Wallace, W. P., Stewart, M. T., Shaffer, T. R, \& Wilson, J. A. (1998).
Are false recognitions influenced by prerecognition processing? Journal of Experimental Psychology: Learning, Memory, \& Cognition, 24, 299-315.

Wallace, W. P., Stewart, M. T., Sherman, H. L., \& Mellor, M. D. (1995). False positives in recognition memory produced by cohort activation. Cognition, 55, 85-113.

Wolters, G., \& Prinsen, A. (1997). Full versus divided attention and implicit memory performance. Memory \& Cognition, 25, 764-771.

APPENDIX

Critical Test Words

\begin{tabular}{|c|c|c|c|}
\hline Test Word & $\begin{array}{l}\text { Substitute } \\
\text { Phoneme }\end{array}$ & Test Word & $\begin{array}{l}\text { Substitute } \\
\text { Phoneme }\end{array}$ \\
\hline Animal & $/ \mathrm{k} /$ & Military & /1/ \\
\hline Ā $\underline{\text { enue }}$ & $/ 1 /$ & $\underline{\bar{M}}$ onument & $/ \mathrm{d} /$ \\
\hline Barbeque & $/ 1 /$ & Narrower & $/ \mathrm{s} /$ \\
\hline Beautiful & $/ \mathrm{m} /$ & Occupation & $/ \mathrm{r} /$ \\
\hline $\bar{B} u l l e t s$ & $/ \mathrm{n} /$ & Order & $/ \mathrm{n} /$ \\
\hline Butterfly & $/ \mathrm{s} /$ & Piano & $/ \mathrm{t} /$ \\
\hline Category & $/ \mathrm{p} /$ & Politician & $/ \mathrm{s} /$ \\
\hline Ceremony & $/ \mathrm{t} /$ & Prosperity & $/ \mathrm{k} /$ \\
\hline $\bar{C}$ Cigarette & $/ \mathrm{s} /$ & $\underline{\text { Religion }}$ & $/ \mathrm{p} /$ \\
\hline Caultivate & $/ \mathrm{s} /$ & $\underline{\underline{R}}$ estaurant & $/ \mathrm{k} /$ \\
\hline Deliberate & /f/ & $\underline{\text { Robber }}$ & $/ \mathrm{k} /$ \\
\hline Discrepancy & $/ 1 /$ & Sanitary & $/ \mathrm{k} /$ \\
\hline Finger & $/ \mathrm{v} /$ & Shallow & $|\theta|$ \\
\hline Eundamental & $/ \mathrm{r} /$ & Significance & $/ \mathrm{r} /$ \\
\hline Hospital & $/ \mathrm{m} /$ & Telegram & $/ \mathrm{b} /$ \\
\hline Interior & $/ \mathrm{b} /$ & Temperature & $/ 1 /$ \\
\hline Isolation & $/ \mathrm{b} /$ & Temporary & $/ \mathrm{s} /$ \\
\hline Lettuce & /f/ & Transportation & $/ g /$ \\
\hline Liberal & $/ \mathrm{n} /$ & $\underline{\text { Valley }}$ & $/ \mathrm{m} /$ \\
\hline$\overline{\text { Memory }}$ & $/ \mathrm{s} /$ & Vitality & $/ \mathrm{r} /$ \\
\hline
\end{tabular}

Note-Early-change and late-change phonemes are underlined.

(Manuscript received December 28, 1999;

revision accepted for publication May 18, 2001.) 